\title{
Exposure to cold and acute upper respiratory tract infection*
}

R. Eccles ${ }^{1}$, J.E. Wilkinson ${ }^{2}$

Common Cold Centre and Healthcare Clinical Trials, Cardiff School of Biosciences, Cardiff University, United Kingdom

${ }^{2}$ Unilever Discover Colworth Park Sharnbrook, Bedfordshire, United Kingdom
Rhinology 53: 99-106, 2015

DOI:10.4193/Rhino14.239

*Received for publication:

September 25, 2014

Accepted: November 11, 2014

\begin{abstract}
The incidence of acute upper respiratory tract viral infections (URTI) is directly correlated to air temperature with most URTI occurring seasonally in cold weather. This review looks at four types of cold exposure and examines the evidence and possible mechanisms for any relationship to URTI. The effects of cold are discussed as: 1) Chilling of the nose and upper respiratory tract by breathing cold air, 2) Chilling of the mouth and upper digestive tract by ingestion of cold drinks and food, 3) Acute chilling of the body surface, and, 4) Chilling of the body as a whole with a fall in body temperature, hypothermia. Some studies were found to support a relationship between breathing cold air and chilling the body surface with the development of URTI, although this area is controversial. No evidence was found in the literature to support any relationship between ingestion of cold drinks and food and URTI, and similarly no evidence was found to link hypothermia and URTI.
\end{abstract}

Key words: cold temperature, common cold, upper respiratory tract infections, hypothermia, mucosal immune response

\section{Literature search and selection}

The PubMed database was searched during January -July 2014 for relevant literature using key words of: exposure to cold, cold temperature, hypothermia, temperature, cold food, cold drink combined with respiratory infection, mucociliary, common cold, influenza, subclinical and sub-clinical, immunity, immune response, phagocytosis. The titles and then abstracts of the literature were reviewed and full papers were obtained of any relevant articles. The literature search dealt with work on humans published in English, although some relevant animal research was also read. Key articles that were of special interest were subject to a citation search using Web of Science in order to expand the literature base, and again titles and abstracts were read in order to identify relevant literature that was obtained as full papers. The bibliographies of all the full papers that were read were searched for relevant literature and this literature was again subjected to citation searches using the Web of Science database.

\section{Introduction}

Acute upper respiratory tract viral infections (URTI) are commonly associated with cold exposure and this may be the origin of the term 'common cold' which implies exposure to cold or a feeling of chilliness and cold. Despite the well established fact that common colds are caused by common cold viruses ${ }^{(1)}$ there is a widely held folklore that common colds are caused by exposure to cold draughts and damp that in some way penetrate the body to cause illness ${ }^{(2)}$. Benjamin Franklin was supposed to have dispelled any relationship between cold exposure and colds in 1773 when he debated that colds were caused by contagion, and that exposure to cold was beneficial ${ }^{(3)}$ but the belief that cold exposure causes common colds still strongly persists amongst populations across the world ${ }^{(2,4-8)}$. This idea has been the subject of a recent review that suggested that exposure to a cold environment did increase the risk of respiratory tract infections and their severity, and proposed that it was important for public health authorities to take measures to prevent 
1. chilling of nasal airway

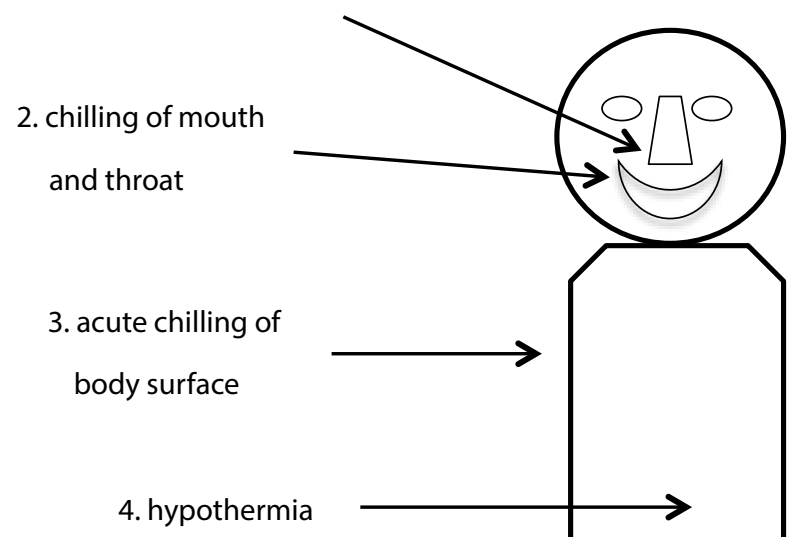

Figure 1. Diagram to illustrate the influence of four different types of chilling. 1) Breathing cold air causes chilling of the nasal airway and upper respiratory tract. 2) Ingestion of cold drinks and food causes chilling of the mouth and upper digestive tract. 3) Acute chilling of the body surface. 4) Chilling of the whole body with hypothermia.

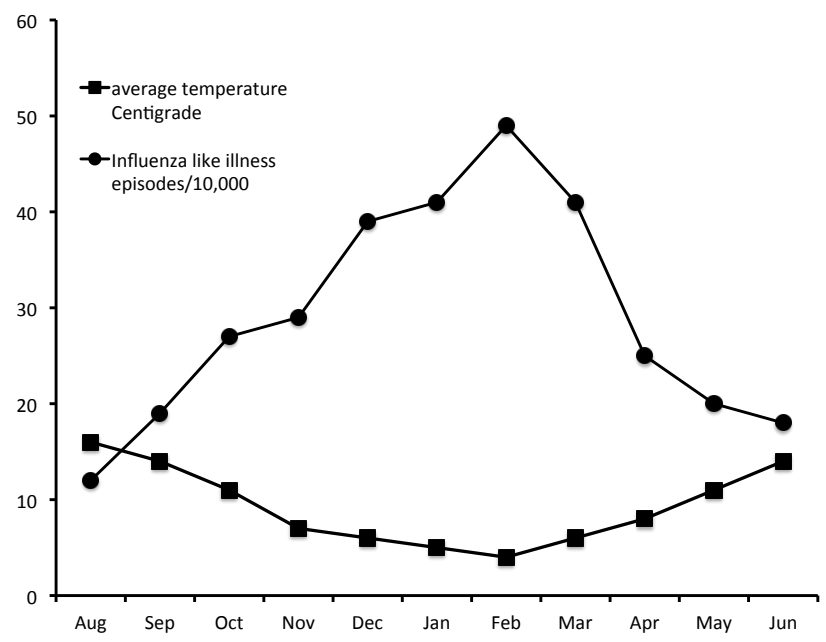

Figure 2. Relationship between average air temperature and the incidence of influenza like illness. As the air temperature falls the incidence of influenza like illness increases. Redrawn from data in a report by Curwen ${ }^{(13)}$. the adverse effects of cold air, especially among vulnerable populations ${ }^{(5)}$. Cold weather is a killer that causes some 250,000 excess winter deaths each year in Europe alone ${ }^{(9)}$. Most of these deaths are due to lower respiratory infections such as pneumonia and bronchiolitis but the infection usually starts as an URTI especially in the case of respiratory syncytial virus and influenza infections ${ }^{(10,11)}$.

The influence of cold weather on the seasonality of URTI has been previously reviewed ${ }^{(12)}$ and this review will focus on the pathophysiological effects of chilling and development of symptoms of URTI. The effects of cold can be categorised as chilling of four different areas of the body as illustrated in Figure 1:

1) Chilling of the nose and upper respiratory tract by breathing cold air, 2) Chilling of the mouth and upper digestive tract by ingestion of cold drinks and food, 3) Acute chilling of parts of the body surface such as the feet, and, 4) Chilling of the body as a whole with a fall in body temperature, hypothermia. The effects of chilling these four body areas will be discussed in terms of how chilling may influence the resistance to infection and the development of symptoms of URTI.

The effects of cold weather on the transmission and survival of viruses, and on crowding and behaviour may influence the incidence of URTI in a population but these topics will not be discussed in this review, which will focus on the effects of chilling on the individual.

\section{Effects of chilling the nose and upper respiratory tract} In periods of cold weather subjects will put on coats and hats to protect against body chilling but it is uncommon for the nose to be protected, and therefore the nose and upper airway are directly exposed to the ambient air temperature and the nasal airway is chilled by every inspiratory breath of cold air. A common factor amongst a wide range of respiratory diseases such as common cold, flu like illness, and pneumonia is a correlation between the incidence of the disease and air temperature, with the incidence of respiratory disease increasing as the air temperature falls $s^{(5,12-16)}$. An example of the relationship of the incidence of one type of URTI (influenza like illness) and air temperature is illustrated in Figure 2. The incidence of influenza like illness is based on the reports from 230 general practitioners in the UK for the period August 1970 to July 1991 and the incidence is expressed as the rate per 10,000 registered patients. Influenza like illness is a general term, which also includes severe common colds, and the figure clearly illustrates that as the air temperature declines the incidence of influenza like illness increases with the peak incidence of illness occurring during the coldest month of February ${ }^{(13)}$. The correlation between air temperature and the incidence of respiratory disease is generally accepted in the literature for respiratory diseases such as common $\operatorname{cold}^{(17,18)}$ and bronchiolitis caused by respiratory syncytial virus (RSV) ${ }^{(19-21)}$ and the primary cause of both diseases involves viral infection of the nasal airway.

The incidence of URTI is only related to cold air temperature when viruses are free to move around a large population of susceptible hosts. The classic study by Paul \& Freese (1933) in an isolated arctic community of some 500 persons clearly demonstrated that during the very cold winter period the weekly incidence of colds gradually fell to almost none as immunity to the viruses developed in the closed community, but then rapidly rose to an epidemic of some 100 cases of colds a week after 
a ship arrived with new subjects with colds and new viruses to which the isolated community had not been previously exposed $^{(22)}$.

Exposure to cold air can cause chilling of the body surface if the subject is not well clothed, and if chilling is prolonged this may cause hypothermia. However, if the subject is well clothed then it is only the face, nasal airway and upper respiratory tract that will be chilled, and this is the assumption made in this section. Although acute chilling of the face can cause reflex cardiovascular and respiratory responses such as bronchoconstriction and bradycardia ${ }^{(23-25)}$ no evidence has been found to indicate that acute facial chilling leads to URTI.

Breathing cold air will not only chill the nasal airway but also cause some drying of the airway, as cold air is dry and will have a drying effect on the airway. It is difficult to separate the effects of cooling and drying on exposure to cold air, especially since airway drying through evaporation will be accompanied by some degree of cooling ${ }^{(26)}$.

The hypothesis that will be proposed in this review is that breathing cold air causes chilling of the nasal airway and this compromises respiratory defence against infection firstly by slowing mucociliary clearance and secondly by inhibiting leucocyte phagocytosis.

\section{Breathing cold air chills the nasal airway}

The air we breathe is warmed and humidified as it passes through the nose and upper airways, so that by the time it reaches the lungs it is warmed to $37^{\circ} \mathrm{C}$ and fully saturated with water vapour ${ }^{(27)}$. In most environments the air we breathe is well below $37^{\circ} \mathrm{C}$, and therefore the nasal airway is always exposed to a degree of heat loss and chilling and the anterior part of the nose will be directly exposed to the ambient temperature. Studies on the human nose have demonstrated that with an inspired air temperature of around $6^{\circ} \mathrm{C}$ the anterior $5 \mathrm{~cm}$ of the nasal respiratory epithelium will be exposed to temperatures between $6^{\circ} \mathrm{C}$ and $20^{\circ} \mathrm{C}$ as the inspired air passes through the nose and is warmed ${ }^{(28)}$. With ambient temperatures at $0^{\circ} \mathrm{C}$, or lower, that are commonly encountered in winter, one would expect an even greater chilling of the nasal airway. Even in a temperate climate such as that of the UK, the annual extremes of air temperature can range from -13 to $+34^{\circ} \mathrm{C}$ (Heathrow airport, London) ${ }^{(29)}$. Work in a cold environment such as in the food industry where workers spend time in refrigerated areas, chills the nasal airway, and such workers have been reported to suffer from an increased incidence of colds compared to the general population $^{(30)}$.

Breathing cold air, especially during exercise when the nasal airflow is increased, will cool and dry the nasal mucosa and act as a nasal irritant ${ }^{(26)}$. The nasal irritation may lead to acute symptoms similar to a common cold with sneezing, nasal congestion and runny nose ${ }^{(31)}$. This type of nasal condition is sometimes referred to as 'skier's nose'(32). These acute nasal symptoms, that may last over a few hours, are not usually confused with the typical symptoms of URTI that may persist for a week or more.

\section{Chilling of the nasal airway compromises respiratory defence} Each day our nose warms, filters and humidifies around 14,000 litres of air ${ }^{(33)}$. This air contains dust that is contaminated with infectious material such as viruses, bacteria and fungi. The nose and upper airways are the most commonly infected area of the body with adults suffering on average 2-5 symptomatic URTI every year and most school children suffering 7-10 colds a year ${ }^{(34)}$. The adenoids at the back of the nose (nasopharynx) act as immune samplers of inspired pathogens and they are the site of the first infection of the nasal airway ${ }^{(35,36)}$. The nose and upper airways have two major defences against infection: firstly, mucociliary clearance of a continuously moving layer of mucus that lines the airway; and secondly, the local innate immune response involving phagocytic leukocytes. Chilling of the airway will compromise both these mechanisms of respiratory defence and predispose to respiratory infection.

\section{Effects of chilling of nose on mucociliary clearance}

Particulate matter deposited in the nose, is trapped on the thin mucus blanket that covers the nasal respiratory epithelium, and then slowly moved by rapidly beating cilia to the nasopharynx, to be swallowed and then sterilised in the acid of the stomach (37). Mucociliary clearance consists of two components; the production of a thin blanket of mucus and the beating of cilia ${ }^{(37,}$ ${ }^{38)}$. Mucociliary clearance is the first line of respiratory defence against infection and anything which compromises mucociliary clearance leads to an increased incidence of respiratory infection ${ }^{(37,38)}$. The rate of clearance of particles deposited on the surface of the respiratory epithelium can be slowed by factors that slow the rate of beating of the cilia, and by factors that decrease the rate of secretion of mucus or increase the viscosity of the mucus ${ }^{(38,39)}$. For example: the beating of the cilia may be slowed by genetic diseases which predispose to ciliary dyskinesia, and these diseases invariably result in chronic infections of the nose, paranasal sinuses, and lower airways ${ }^{(40)}$; and the viscosity of the mucus blanket is increased by diseases such as cystic fibrosis, and this results in frequent and often chronic infection of the airway ${ }^{(38)}$.

Human mucociliary clearance is slowed on exposure to cold air (37) and cilia stop beating at $4^{\circ} \mathrm{C}$ and then do not start beating until the temperature is $10^{\circ} \mathrm{C}^{(41)}$. The decrease in temperature, by slowing metabolic activity, is likely to influence the rate of mucociliary clearance by slowing ciliary beat frequency and decreasing the rate of secretion of mucus. Depending on the magnitude of the decrease in temperature it is also likely to cause an increase in the viscosity of respiratory mucus ${ }^{(42)}$. Exposure to cold air decreases the temperature of the nasal 
respiratory epithelium and that this causes a decrease in the rate of mucociliary clearance that compromises respiratory defence to infection ${ }^{(43)}$.

\section{Effects of airway cooling on local immune response of the airway}

The immediate local innate immune response of the nasal respiratory epithelium to viral and bacterial infection involves a non-specific response of polymorphonuclear leukocytes and lymphocytes. Phagocytic leukocytes continuously pass through the nasal epithelium into nasal mucus and scavenge any particulate matter such as viruses and bacteria. Nasal mucus is normally clear and colourless but with infection there is a massive movement of leukocytes through the nasal epithelium into the nasal airway and the colour of nasal mucus changes from clear to yellow to green as the concentration of leukocytes increases in the mucus ${ }^{(44)}$. The non-specific response involves, phagocytosis, the generation of viricidal and bactericidal superoxides, the generation of complement factors, and the generation of chemical mediators such as bradykinin and prostaglandins, which play an active role in local defence ${ }^{(45)}$. Like all biological processes that are dependent on metabolic activity, the local immune response of the respiratory epithelium is slowed by a decrease in temperature $\mathrm{e}^{(46-48)}$.

Chilling of the nasal airway may compromise the local immune defences in the adenoid tissue in the nasopharynx as cooling of the adenoids will slow phagocytosis of viruses and bacteria and predispose to infection. The adenoids and nasopharynx have been shown to harbour respiratory viruses during the winter colds season ${ }^{(49,50)}$ and it is possible that cooling of the adenoids with cold air could convert a sub-clinical infection into a clinical symptomatic URTI.

\section{Effects of chilling the mouth and upper digestive tract} The idea that cold food and drink harms the body may relate back to Hippocratic ideas (Hippocates 460-370 BC) that good health depended on a balance between four qualities: heat, cold, wetness and dryness ${ }^{(51)}$. This ancient idea still persists in the present day, and the cause of URTI is commonly attributed to an imbalance of 'hot' and 'cold' in the body, especially in less welleducated rural communities ${ }^{(7,52)}$. The temperature imbalance is sometimes believed to be caused by ingestion of cold food and cold water that may disturb the humoral balance between 'hot' and 'cold' in the body ${ }^{(52)}$. Cold food is often a left-over food that has been saved for later eating, such as cold rice dishes, and rural communities in Bangladesh believe that eating this cold food may cause URTI and more serious infections such as pneumonia ${ }^{(52)}$. Drinking cold water is also believed to be a cause of respiratory infections by disturbing the body's balance of 'hot' and 'cold'(7).

It may not be surprising that the folk-lore in less well-educated rural communities in Bangladesh explains the cause of URTI and other respiratory infections by exposure to cold such as ingestion of cold food and drinks, but even in more educated and Westernised communities the idea that ingestion of cold food and drink such as ice cream causes sore throat and URTI still persists in folk-lore and culture. Ice cream consumption is quite seasonal in some countries such as Turkey because of the belief that ingestion of cold products may be harmful during the colder winter period. Independent consumer research in Turkey indicates that over two thirds of those questioned report that they only eat ice cream in summer, with $43 \%$ agreeing with the statement that ice cream causes sore throat (Unilever, 2012)(53). The belief that cold foods and drinks may have harmful effects if ingested during cold weather is often linked to the idea that in winter it is best to keep warm, and that cold foods and drinks may in some way cool the body and make it more susceptible to common illnesses such as sore throat and common cold. A January 2009 Euromonitor report indicates that the sales of ice cream in Turkey are reported to be mainly in the summer months because "there's a widespread belief among Turks that eating ice cream during the frigid winter months can spark maladies such as throat infections ${ }^{(54)}$.

A sore throat is often the first sign of a developing URTI as the respiratory viruses have been shown to first infect the adenoid tissue in the nasopharynx at the back of the nose ${ }^{(35)}$. Respiratory viruses can be found in the nasopharynx and adenoids during the winter common cold season ${ }^{(49,50)}$ but there is no evidence that these viruses infect the mouth and digestive tract and this may be because of a lack of relevant virus receptors in the mouth and digestive tract such as intercellular adhesion molecule- 1 which acts as a receptor for rhinoviruses and which is found expressed in adenoid tissue ${ }^{(55)}$. Cold food and drink cool the mouth and upper digestive tract (oesophagus) and although the nasopharynx, at the back of the nose, is above and close to the digestive tract, it is unlikely to be significantly cooled by food and drink, as it is part of the nasal airway and not the digestive tract. As speculated above for the nasal airway, chilling of the adenoids could inhibit the local innate immune response of the adenoids and predispose to development of URTI but because of the lack of contact of the adenoids with ingested food and fluid this does not seem likely. Application of an ice-lolly to the skin will induce temperature regulation reflexes such as shivering and skin vasoconstriction ${ }^{(56)}$, but there is no evidence that application of the same cold stimulus to the mouth causes any temperature regulating reflexes such as vasoconstriction ${ }^{(57)}$. This may be because the skin cold receptors are involved in temperature regulation as exteroreceptors whereas the cold receptors in the mouth are involved in the appreciation of food and drink rather than temperature regulation. Chilling of the body surface causes shivering and this may 
be perceived as unpleasant, especially during cold weather but chilling of the mouth is may be perceived as pleasant because the cool stimulus satiates thirst ${ }^{(58,59)}$.

No scientific or clinical evidence has been found to support the idea that ingestion of cold products such as ice cream predisposes to sore throat or common cold. On the contrary rather than predisposing to causing sore throat there is a traditional use of cold products such as ice cream and ice lollies as a therapy to reduce post-operative pain of sore throat after tonsillectomy in children ${ }^{(60)}$. In a recent clinical study on 92 children who had undergone tonsillectomy, Sylvester et al. reported that ingestion of an ice lolly reduced sore throat pain for up to one hour after ingestion of the lolly ${ }^{(60)}$. Children undergoing tonsillectomy are suffering from inflammation and infection of the tonsils and throat, and there is no evidence that ingestion of cold products exacerbates tonsillitis or causes sore throat, rather the opposite effect seems to be more likely, that cold products are a useful therapy for sore throat. The mechanism of this analgesic action of throat cooling has been proposed to be due to effects on cold receptors in the throat ${ }^{(61)}$. Sore throat pain is caused by the effects of inflammatory mediators such as bradykinin and prostaglandins on pain nerve endings, and the pain is increased by the warming effects of throat inflammation ${ }^{(62)}$. Ice treatments for tonsillectomy pain may work in two ways, firstly by lowering the temperature of pain nerve endings, and secondly by activating TRPM8 cold receptors (Transient Receptor Potential Melastin 8). TRPM8 is a menthol receptor, which evokes a cool sensation when activated by temperatures below $25^{\circ} \mathrm{C}$ and TRPM8 activation, has been shown to elicit analgesia in several different pain models ${ }^{(63)}$. TRPM8 cold receptors will be activated by any cold stimulus in the mouth, such as ice cream and ice lollies. It is interesting that menthol lozenges, which give a cool sensation in the mouth, are one of the most popular treatments for sore throat and menthol is a stimulant of the TRPM8 cold receptors ${ }^{(64)}$.

The cooling of the mouth and throat by ingestion of cold food and drink will only cause a brief period of cooling over a few minutes, and any effects on the defences against infection will be short lived. This contrasts with cooling of the nasal airway in cold weather as discussed above, when the nasal airway may be exposed to cold air for many hours. The volumes of cold air are also much greater than the volume of any cold food and drink, as we breathe over 14,000 litres of air each day, whereas total food and drink only involve a few litres of intake each day.

\section{Effects of acute chilling the body surface}

It is well established that chilling of the body surface will cause a pronounced vasoconstriction of blood vessels in the nose and upper airway. Mudd et al. ${ }^{(65)}$ reported that chilling of the body surface in human volunteers caused a pronounced ischaemia of the nasal mucosal surface that was measured as a fall in temperature via a nasal thermistor. In some subjects the depression of nasal mucosal temperature was more than $6^{\circ} \mathrm{C}$. Spiesman ${ }^{(66)}$ demonstrated that cold stimuli such as cold air or ice filled cups, applied to the exposed areas of the body such as the back and feet, caused a pronounced decrease in the temperature of the nasal mucous membrane which was interpreted as being due to nasal vasoconstriction. Spiesman ${ }^{(66)}$, also reported that in subjects who were prone to many upper respiratory tract infections there was a more prolonged nasal vasoconstriction compared to normal subjects, with the nasal vasoconstriction lasting for several hours in some subjects. Drettner ${ }^{(67)}$ conducted a series of experiments on 50 subjects that demonstrated a marked vasoconstriction and blanching of nasal blood vessels, on cooling the back or placing the feet in cold water. The nasal vasoconstrictor response was greater at 90 minutes in those subjects who had eight or more colds per year compared to a group that had 0-3 colds per year. The idea that chilling of the body surface could predispose to infection of the upper airway, by causing vasoconstriction in the mucous membranes lining the airway, was first proposed by Mudd and Grant ${ }^{(68)}$. In a study on human volunteers Mudd and Grant ${ }^{(68)}$ reported that cooling of the skin caused a reflex vasoconstriction and ischaemia of the mucous membranes of the palate, faucial tonsils, oropharynx and nasopharynx. The mechanism of compromising nasal defences against infection is that the vasoconstriction reduces the supply of leucocytes to the lining of the nose and adenoids and therefore reduces the elimination of viruses from the nose ${ }^{(69,70)}$.

The hypothesis that chilling the body surface causes constriction of the mucosal blood vessels in the nose and throat and that this compromises local immune responses and allows a sub-clinical viral infection to develop into a clinical infection has been previously reviewed ${ }^{(70)}$. This hypothesis is controversial because some laboratory studies have failed to demonstrate any increased susceptibility to respiratory viral infection on acute cold exposure ${ }^{(71-73)}$. Cold exposure in these studies involved exposure of subjects for $2-4$ hours in cold rooms at $10-60^{\circ} \mathrm{F}^{(72)}$ and submersion in water baths at $32^{\circ} \mathrm{C}$ for several hours ${ }^{(73)}$. A criticism that can be made against these laboratory experiments, is that they do not mimic the natural exposure to viruses and natural chilling. The experiments are by necessity concerned with artificial inoculation of virus into the nose and then monitoring the development of symptoms. In these respects, the negative results of the laboratory experiments do not destroy the hypothesis, that cooling of the body surface may convert a sub-clinical to a clinical infection due to a local inhibition of respiratory defence in the nose and upper airway. Infection caused by inoculating a virus into the nose is quite different from an ongoing sub-clinical infection. The sub-clinical infection may need only a slight inhibition of local airway defences to convert 
to a clinical infection.

A study on chilling of the feet and onset of common cold symptoms in human subjects does provide some support for the hypothesis that chilling can lead to an URTI(74). In this study, 180 subjects were randomly allocated to receive either a foot chill or control procedure. 13/90 subjects who were chilled reported they were suffering from a cold in the $4 / 5$ days after the procedure compared tp $5 / 90$ control subjects $(p=0.047)$. The chilled subjects also had significantly greater symptom severity scores for days $1-4$ following chilling $(p=0.013)$. The major weakness of this study is that there was no virology undertaken to prove that the colds were URTI. More research with larger groups and virology is needed to test this controversial hypotheis ${ }^{(5,75)}$.

\section{Effects of hypothermia}

It is difficult to separate the effects of hypothermia from the three other types of chilling discussed above as a fall in core body temperature is likely to be preceded by exposure to chilling of the body surface and may also include breathing cold air. Most studies on hypothermia and respiratory infection have been concerned with the development of more serious respiratory infections such as pneumonia and a literature search has not found any studies on hypothermia and URTI.

Induced hypothermia is used to protect the brain and other organs after trauma and during some types of surgery. Evidence from clinical and in vitro studies shows that hypothermia can impair immune function ${ }^{(76)}$. Inhibition of inflammatory responses may be one of the mechanisms through which hypothermia protects the brain and other organs from damage. Hypothermia inhibits the release of various pro-inflammatory cytokines ${ }^{(77)}$ and suppresses chemotactic migration of leukocytes and phagocytosis $^{(47)}$.

Clinically induced hypothermia has been implicated as a cause of respiratory infections such as pneumonia ${ }^{(5)}$. In a study examining the safety of moderate hypothermia it was found that pneumonia was a common complication and occurred in $48 \%$ of patients ${ }^{(78)}$. A meta-analysis of data from eight high quality trials demonstrated an increase incidence in pneumonia of 51\% in patients treated with hypothermia compared with $23 \%$ in the normothermia group ${ }^{(79)}$. The role of clinically induced hypothermia in predisposing towards respiratory infection is complicated by the many other procedures that patients may undergo whilst in intensive care units such as the use of antibiotics and selective decontamination of the digestive tract, and some reports have indicated that these procedures can greatly reduce the risk of infection ${ }^{(80)}$.

Although one might expect that hypothermia would always cause an inhibition the immune and inflammatory responses to infection, the current consensus is that a mild decrease in core temperature $\left(\sim 0.5^{\circ} \mathrm{C}\right.$ has little effect or even a stimulatory effect on immune function, but that modest $\left(\sim 1^{\circ} \mathrm{C}\right)$ and severe $\left(\sim 4^{\circ} \mathrm{C}\right)$ decreases in core temperature inhibit immune function ${ }^{(75)}$.

\section{Discussion and conclusions}

The relationship between cold air and the incidence of URTI is an established fact, but there is controversy about 'if 'and 'how' cold air may cause or predispose to URTI. The symptoms of an uncomplicated URTI may be a nuisance for a week or so, but the viruses that cause URTI also cause considerable morbidity and mortality by predisposing to serious lower respiratory tract infections such as pneumonia, especially in infants and the elderly, and this makes the control of URTI in the community a more serious issue for discussion ${ }^{(5,10)}$. If breathing cold air is involved in determining the incidence of URTI, then simple measures such as wearing a scarf across the face to prevent nasal cooling could be promoted to reduce the incidence of URTI and the risk of lower respiratory tract infections in the elderly ${ }^{(12)}$.

A relationship between chilling of the body surface and URTI is even more controversial than that for exposure to breathing cold air and URTI. Causality between chilling and URTI is firmly rooted in the folk-lore throughout the world ${ }^{(2,52,81)}$ but experiments designed to test this hypothesis have given conflicting results and more research is needed in this area.

The fear of developing a URTI or sore throat on consuming cold foods such as ice cream or taking cold drinks in cold weather persists in some countries ${ }^{(7)}$ but no evidence has been found to support this idea. No scientific or clinical evidence has been found to support the idea that ingestion of cold products such as ice cream predisposes to sore throat or common cold and there is no satisfactory mechanism to explain how ingestion of cold products could influence onset of URTI .

Hypothermia may be a cause of infections such as pneumonia but no evidence has been found to indicate that hypothermia causes URTI.

Cold and URTI are synonymous but there is still much more research needed to show how the two can be linked together.

\section{Authorship contribution}

RE: Literature search and drafting of document; JEW: Original ideas on effects of cold foods on infection. Reviews of manuscript and criticism of ideas.

\section{Conflict of interest}

RE has acted as a consultant to Unilever on the effects of cold exposure on the incidence of common colds. JEW is an employee of Unilever. 


\section{References}

1. Weber $\mathrm{O}$. The role of viruses in the etiology and pathogenesis of common cold. In: Eccles R, Weber O, editors. Common Cold. Basel: Birkhauser Verlag; 2009. p. 107-147.

2. Helman CG. "Feed a cold, starve a fever" Folk models of infection in an English suburban community, and their relation to medical treatment. Cul Med Psychiatry. 1978; 2: $107-$ 137.

3. Franklin B. Causes of Colds. Letter to Dr Benjamin Rush. 1773.

4. Lyun BF, Tomson G. Acute respiratory infections--mothers' perceptions of etiology and treatment in south-western Nigeria. Soc Sci Med. 1996; 42: 437-445.

5. Mourtzoukou EG, Falagas ME. Exposure to cold and respiratory tract infections. Int J Tuberc Lung Dis. 2007; 11: 938-943.

6. Au TK-F, Chan CKK, Chan T-K, Cheung MWL, Ho JYS, Ip GWM. Folkbiology meets microbiology: A study of conceptual and behavioral change. Cognitive Psychology. 2008; 57: 1-19.

7. Nizame FA, Nasreen S, Unicomb L, et al. Understanding community perceptions, social norms and current practice related to respiratory infection in Bangladesh during 2009: a qualitative formative study. BMC public health. 2011; 11: 901.

8. Sigelman CK. Age and Ethnic Differences in Cold Weather and Contagion Theories of Colds and Flu. Health Educ Behav. 2012; 39: 67-76

9. Mercer JB. Cold--an underrated risk factor for health. Environ Res. 2003; 92: 8-13.

10. Hashem M, Hall CB. Respiratory syncytial virus in healthy adults: the cost of a cold. Clin Virol. 2003; 27:14-21.

11. Rello J, Pop-Vicas A. Clinical review: primary influenza viral pneumonia. Crit Care. 2009; 13: 235

12. Eccles R. An explanation for the seasonality of acute upper respiratory tract viral infections. Acta Oto-Laryngol. 2002; 122: 183-191.

13. Curwen M. Excess winter mortality in England and Wales with special reference to the effects of temperature and influenza. In: Charlton J, Murphy M, editors. The health of adult Britain 1841- 1994. London: The Stationery Office; 1997. p. Chapter 13, 205216.

14. Hajat S, Bird W, Haines A. Cold weather and GP consultations for respiratory conditions by elderly people in 16 locations in the UK Eur J Epidemiol. 2004; 19: 959-968.

15. Makinen TM, Juvonen R, Jokelainen J, Harju TH, Peitso A, Bloigu A, et al. Cold temperature and low humidity are associated with increased occurrence of respiratory tract infections. Respir Med. 2009; 103: 456-462.

16. Davis RE, Rossier CE, Enfield KB. The impact of weather on influenza and pneumonia mortality in New York City, 1975-2002: a retrospective study. PLoS One. 2012;7(3): e34091.

17. Van Loghem JJ. An epidemiological contri- bution to the knowledge of the respiratory system. J Hygiene. 1928; 28: 33-54.

18. Lidwell OM, Morgan RW, Williams RE. The epidemiology of the common cold. IV. The effect of weather. J Hyg (Lond). 1965; 63: 427-439.

19. Crowcroft N, Cutts F, Zambon M Respiratory syncytial virus: an underestimated cause of respiratory infection, with prospects for a vaccine. Communicable Disease and Public Health. 1999; 2: 234-241.

20. Chan PW, Chew FT, Tan TN, Chua KB, Hool PS. Seasonal variation in respiratory syncytial virus chest infection in the tropics. Pediatr Pulmonol. 2002; 34: 47-51.

21. Hervas D, Reina J, Hervas JA. Meteorologic Conditions and Respiratory Syncytial Virus Activity. Pediatr Infect Dis J. 2012; 31: E176-E181.

22. Paul JH, Freese HL. An epidemiological and bacteriological study of the "common cold" in an isolated arctic community (Spitsbergen). Am J Hygiene. 1933; 17: $517-$ 535 .

23. Josenhans WT, Melville GN, UImer WT. The effect of facial cold stimulation on airway conductance in healthy man. Can J Physiol Pharmacol. 1969; 47: 453-457.

24. Koskela H, Tukiainen H. Facial cooling, but not nasal breathing of cold air, induces bronchoconstriction: a study in asthmatic and healthy subjects. Eur Respir J. 1995; 8 : 2088-2093.

25. Argacha JF, Xhaet O, Gujic M, et al. Facial cooling and peripheral chemoreflex mechanisms in humans. Acta Physiologica. 2008; 194: 161-170.

26. Giesbrecht GG. The respiratory system in a cold environment. Aviat Space Environ Med. 1995; 66: 890-902

27. Cole P. Modification of inspired air. In: Mathew OP, Sant' Ambrogio G, editors. Respiratory Function of the Upper Airway. New York: Marcell Dekker; 1988. p. 415-445.

28. Webb P. Respiratory heat loss in cold. J Applied Physiol. 1951; 4: 378-382.

29. Lacy R. Climate and building in Britain. London: Her Majesty's Stationery Office; 1977.

30. Griefahn B, Mehnert P, Brode P, Forsthoff A. Working in moderate cold: A possible risk to health. J Occup Health. 1997; 39: 36-44.

31. Koskela HO. Cold air-provoked respiratory symptoms: the mechanisms and management. Int J Circumpolar Health. 2007; 66: 91-100.

32. Silvers WS. The skier's nose: a model of coldinduced rhinorrhea. Ann Allergy. 1991; 67: 32-36.

33. Cole P. Modification of inspired air. In: Proctor DF, Andersen I, editors. The nose, upper airways physiology and the atmospheric environment. Amsterdam: Elsevier; 1982. p. 351-376.

34. Johnston S, Holgate S. Epidemiology of viral respiratory infections. In: Myint S, Taylor-Robinson D, editors. Viral and other infections of the human respiratory tract.
London: Chapman \& Hall; 1996. p. 1-38.

35. Winther B, Gwaltney JM, Mygind N, Turner $R B$, Hendley $O$. Sites of rhinovirus recovery after point innoculation of the upper airway. J Am Med Assoc. 1986;256(13):1763 - 1767.

36. Hellings $P$, Jorissen $M$, Ceuppens JL. The Waldeyer's ring. Acta Otorhinolaryngol Belg. 2000; 54: 237-241

37. Proctor DF. The mucociliary system. In: Proctor DF, Andersen I, editors. The nose Upper airway physiology and the atmospheric environment. Amsterdam: Elsevier Biomedical Press; 1982. p. 245-278.

38. Quraishi MS, Jones NS, Mason J. The rheology of nasal mucus: a review. Clin Otolaryngol Allied Sci. 1998; 23: 403-413.

39. Baetjer A. Effect of ambient temperature and vapor pressure on cilia-mucus clearance rate. J Applied Physiol. 1967; 23: 498504

40. Eliasson R, Mossberg B, Camner P, Afzelius $B A$. The immotile cilia syndrome: A congenital ciliary abnormality as an etiologic factor in chronic airway infections and male sterility. New Engl J Med. 1977; $297: 1-6$.

41. Smith CM, Hirst RA, Bankart MJ, et al. Cooling of cilia allows functional analysis of the beat pattern for diagnostic testing. Chest. 2011; 140: 186-190.

42. Humphries S. A physical explanation of the temperature dependence of physiological processes mediated by cilia and flagella. Proc Natl Acad Sci U S A. 2013; 110: 1469314698.

43. Diesel D, Lebel J, Tucker A. Pulmonary particle deposition and airway mucociliary clearance in cold-exposed calves. Am J Vet Res. 1991; 52: 1665-1671.

44. Eccles R. Understanding the symptoms of the common cold and influenza. Lancet Infect Dis. 2005; 5: 718-725.

45. Roitt I. Essenial immunology. Oxford: Blackwell Scientific Publications; 1991.

46. Djaldetti M, Salman H, Bergman M, Djaldetti $\mathrm{R}$, Bessler $\mathrm{H}$. Phagocytosis-the mighty weapon of the silent warriors. Microsc Res Tech. 2002; 57: 421-431.

47. Salman $H$, Bergman $M$, Bessler $H$, Alexandrova S, Beilin B, Djaldetti M. Hypothermia affects the phagocytic activity of rat peritoneal macrophages. Acta Physiologica Scandinavica. 2000; 168: 431436.

48. Salman $H$, Bergman $M$, Bessler $H$, Alexandrova S, Djaldetti M. Ultrastructure and phagocytic activity of rat peritoneal macrophages exposed to low temperatures in vitro. Cryobiology. 2000; 41: 66-71.

49. Rihkanen $\mathrm{H}$, Carpen $\mathrm{O}$, Roivainen $\mathrm{M}$, Vaheri A, Pitkaranta A. Rhinovirus in adenoid tissue. Int J Pediatr Otorhinolaryngol. 2004; 68: 903-908.

50. Pitkaranta A, Roivainen $M$, Blomgren K, Peltola J, Kaijalainen T, Raty R, et al. Presence of viral and bacterial pathogens in the nasopharynx of otitis-prone children. A prospective study. Int J Pediatr 
Otorhinolaryngol. 2006; 70: 647-654.

51. Mennell S, Murcott A, Van Otterloo A. Beliefs and practices about food and health: The lay perspective. The sociology of food: eating, diet, and culture. London: Sage Publications; 1992. p. 42-47.

52. Rashid SF, Hadi A, Afsana K, Begum SA Acute respiratory infections in rura Bangladesh: cultural understandings, practices and the role of mothers and community health volunteers. Trop Med Int Health. 2001; 6: 249-255.

53. Unilever. Personal communication.

54. Weiss L. Ice Cream, A Global History. London: Reaktion Books; 2011.

55. Winther B, Greve JM, Gwaltney JM, Jr., et al Surface expression of intercellular adhesion molecule 1 on epithelial cells in the human adenoid. J Infect Dis. 1997; 176: 523-525.

56. Clark RP, Goff MR, Mullan BJ. Skin temperatures during sunbathing and some observations on the effect of hot and cold drinks on these temperatures [proceedings]. J Physiol. 1977; 267: 8P-9P.

57. Drettner B. Vascular Reactions on the Intake of Food and Drink of Various Temperatures. Acta Otolaryngol. 1964; suppl 188: 249-257.

58. Eccles R. Role of cold receptors and menthol in thirst, the drive to breathe and arousal. Appetite. 2000; 34: 29-35.

59. Eccles R, Du-Plessis L, Dommels Y, Wilkinson JE. Cold pleasure. Why we like ice drinks, ice-lollies and ice cream. Appetite. 2013; 71C: $357-360$

60. Sylvester DC, Rafferty A, Bew S, Knight LC. The use of ice-lollies for pain relief postpaediatric tonsillectomy. A single-blinded, randomised, controlled trial. Clin Otolaryngol. 2011; 36: 566-570.

61. Bathala S, Eccles R. RE: The use of ice lollies for pain relief post-paediatric tonsillectomy. Clin Otolaryngol. 2012; 37: 162-163.

62. Bathala S, Eccles R. A review on the mechanism of sore throat in tonsillitis. J Laryngol Otol. 2013: 127: 227-232.

63. Chung MK, Jung SJ, Oh SB. Role of TRP channels in pain sensation. Adv Exp Med
Biol. 2011; 704: 615-636.

64. Gavva NR, Davis C, Lehto SG, Rao S, Wang W Zhu DX. Transient receptor potential melastatin 8 (TRPM8) channels are involved in body temperature regulation. Mol Pain. 2012; 8: 36 .

65. Mudd S, Goldman A, Grant SB. Reactions of the nasal cavity and postnasal space to chilling of the body surface. J Exp Med. 1921; 34: 11-45

66. Spiesman I. Vasomotor responses of the mucosa of the upper respiratory tract to thermal stimuli. Am J Physiol. 1936; 115: 181-187.

67. Drettner B. Vascular reactions of the human nasal mucosa on exposure to cold. Acta Oto-Laryngologica (Stockholm). 1961; Suppl 166: 1-109.

68. Mudd S, Grant S. An experimental study of a possible mechanism for the excitation of infections of the pharynx and tonsil. Am J Physiol. 1919; 49: 144-145.

69. Taylor H, Dyrenforth L. Chilling of the body surfaces. Its relationship to aural and sinus infections. JAMA. 1938; 111: 1744-1747.

70. Eccles R. Acute cooling of the body surface and the common cold. Rhinology. 2002; 40: 109-114.

71. Andrewes $\mathrm{CH}$. Adventures among viruses. III. The puzzle of the common cold. New Eng Med J. 1950; 242: 235-240.

72. Dowling HF, Jackson GG, Spiesman IG Inouye T. Transmission of the common cold to volunteers under controlled conditions. II. The effect of chilling of the subject upon susceptibility. Am J Hygiene. 1958, 66: 59-65.

73. Douglas RGJ, Lindgren KM, Couch RB Exposure to cold environment and rhinovirus common cold. Failure to demonstrate effect. New Eng J Med. 1968; 279: 742-747.

74. Johnson C, Eccles R. Acute cooling of the feet and the onset of common cold symptoms. Fam Pract. 2005;2: 608-613.

75. Walsh NP, Gleeson M, Pyne DB, et al. Position statement. Part two: Maintaining immune health. Exercise Immunol Rev.
2011: 17: 64-103.

76. Polderman KH. Application of therapeutic hypothermia in the intensive care unit. Opportunities and pitfalls of a promising treatment modality-Part 2: Practical aspects and side effects. Intensive Care Med. 2004 30: 757-769.

77. Kimura A, Sakurada S, Ohkuni H, Todome Y, Kurata K. Moderate hypothermia delays proinflammatory cytokine production of human peripheral blood mononuclear cells. Critical Care Med. 2002; 30: 1499-1502.

78. Schwab S, Georgiadis D, Berrouschot J, Schellinger PD, Graffagnino C, Mayer SA. Feasibility and safety of moderate hypothermia after massive hemispheric infarction. Stroke. 2001; 32: 2033-2035.

79. Peterson K, Carson S, Carney N Hypothermia treatment for traumatic brain injury: a systematic review and meta-analysis. J Neurotrauma. 2008; 25: 62-71.

80. Kamps M, Bisschops LA, van der Hoeven JG, Hoedemaekers CW. Hypothermia does not increase the risk of infection: a case control study. Crit Care. 2011; 15: R48.

81. Baer RD, Weller SC, Pachter L, et al. Crosscultural perspectives on the common cold: Data from five populations. Hum Organ. 1999; 58: 251-260

Professor R. Eccles

Common Cold Centre and Healthcare

Clinical Trials

Cardiff School of Biosciences

Cardiff University

Cardiff CF10 3 AX

United Kingdom

Tel: +44-(0)292-087 4102

Fax: +44-(0)292-087 4093

E-mail: eccles@cardiff.ac.uk 